\title{
Technology in precision viticulture: a state of the art review
}

This article was published in the following Dove Press journal:

International Journal of Wine Research

18 May 2015

Number of times this article has been viewed

\section{Alessandro Matese \\ Salvatore Filippo Di \\ Gennaro 1,2}

'Institute of Biometeorology, National Research Council (IBIMET-CNR), Florence, Italy; ${ }^{2}$ Department of Agricultural, Food and Environmental Sciences, University of Perugia, Perugia, Italy
Correspondence: Alessandro Matese Institute of Biometeorology, National Research Council (IBIMET-CNR), Via Caproni 8, 50145 Florence, Italy Tel +39055 3033 7II; +393209223934 Fax +39055 308910

Email a.matese@ibimet.cnr.it
Abstract: Precision viticulture aims to maximize the oenological potential of vineyards. This is especially true in regions where the high quality standards of wine production justify the adoption of site-specific management practices to simultaneously increase both quality and yield. The introduction of new technologies for supporting vineyard management allows the efficiency and quality of production to be improved and, at the same time, reduces the environmental impact. The rapid evolution of information communication technologies and geographical science offers enormous potential for the development of optimized solutions for distributed information for precision viticulture. Recent technological developments have allowed useful tools to be elaborated that help in the monitoring and control of many aspects of vine growth. Precision viticulture thus seeks to exploit the widest range of available observations to describe the vineyard spatial variability with high resolution, and provide recommendations to improve management efficiency in terms of quality, production, and sustainability. This review presents a brief outline of state of the art of technologies in precision viticulture. It is divided in two sections, the first focusing on monitoring technologies such as geolocating and remote and proximal sensing; the second focuses on variable-rate technologies and the new agricultural robots.

Keywords: remote sensing, proximal sensing, variable-rate technology, robot

\section{Introduction}

In a context of growing competition on international markets, it becomes of utmost importance to achieve higher quality standards in the vineyard. This has led to a radical renewal of viticulture and a review of agricultural techniques, with the aim of maximizing quality and sustainability through the reduction and more efficient use of production inputs such as energy, fertilizers and chemicals, and minimizing input costs while ensuring the preservation of the environment. The concept of precision viticulture is a step in this direction, being a differentiated management approach aiming to meet the real needs of each parcel within the vineyard. Several authors have studied precision viticulture in Australia and in Europe. ${ }^{1-14}$ Vineyards are characterized by a high heterogeneity due to structural factors such as the pedo-morphological characteristics, and other dynamics such as cropping practices and seasonal weather. ${ }^{15}$ This variability causes different vine physiological response, with direct consequences on grape quality. ${ }^{16}$ Vineyards therefore require a specific agronomic management to satisfy the real needs of the crop, in relation to the spatial variability within the vineyard. ${ }^{17}$ The introduction of new technologies for supporting vineyard management allows the efficiency and quality of production to be improved and, at the same time, reduces the environmental impact. Recent technological developments have allowed useful tools 
to be elaborated that help in the monitoring and control of many aspects of vine growth. Remote and proximal sensing sensors become strong investigation instruments of the vineyard status, such as water and nutrient availability, plant health and pathogen attacks, or soil conditions. Precision viticulture thus seeks to exploit the widest range of available observations to describe the vineyard spatial variability with high resolution, and provide recommendations to improve management efficiency in terms of quality, production, and sustainability.

This paper presents a review of technologies used in precision viticulture. It is divided in two main sections. The first one focuses on monitoring technologies, which are the basis of mapping spatial variability; the second part discusses technologies utilized to provide site-specific agronomic inputs, identified as variable-rate technologies (VRTs) and "agbot" systems.

\section{Monitoring technologies}

The primary objective of the monitoring process is acquisition of the maximum amount of georeferenced information within the vineyard. A wide range of sensors aiming to monitor different parameters that characterize the plant growth environment are employed in precision viticulture for remote and proximal monitoring of geolocated data.

\section{Geolocation}

Georeferencing is the process of establishing the relationship between spatial information and its geographical position. This makes a comparison possible among the different spatial data detected in the vineyard, such as soil physical properties, yield, and water or fertilizer contents. ${ }^{18}$ The Global Positioning System (GPS) is a space-based satellite navigation system that provides users with a highly accurate, 3D position $(\mathrm{x}, \mathrm{y}, \mathrm{z})$ and rapid and timely information. While a GPS receiver calculates its position on earth based on the information it receives from four or more located satellites, with about 3-15 $\mathrm{m}$ accuracy, the differential techniques provide centimeter location accuracy, thanks to a network of fixed, groundbased reference stations to correct the positions indicated by the satellite systems with known fixed positions. This type of GPS technology is useful in performing tasks requiring high precision, such as crop mapping, automatically driven farm vehicles, soil sampling, and distribution of fertilizers and pesticides at variable rates.

\section{Remote sensing}

Remote sensing techniques rapidly provide a description of grapevine shape, size, and vigor and allow assessment of the variability within the vineyard. This is image acquisition at a distance with different scales of resolution, able to describe the vineyard by detecting and recording sunlight reflected from the surface of objects on the ground. ${ }^{19}$

Remotely sensed data permit the plant physiology to be described by means of vegetation indices calculation, such as the well-known normalized difference vegetation index (NDVI), which exploits the different response of vegetation to the visible (red) and near-infrared spectral bands that are closely related to crop status. ${ }^{20}$ Canopy reflectance, in the visible and near-infrared bands, is strongly dependent on both structural (leaf area index [LAI]) and biochemical properties (chlorophyll content) of the canopy. ${ }^{21}$ The combination of vine-leaf biomass and photosynthetic potential has been defined as photosynthetically active biomass (PAB), and remote sensing can detect $\mathrm{PAB}$ through the synergetic effect of individual pixel values (photosynthetic potential) and pixel distribution (biomass) in the spectral signature. ${ }^{22}$ Grapevine $\mathrm{PAB}$ is influenced by site-specific geo-pedo-morphological conditions, and their variation within a vineyard causes a spatial variation in canopy characteristics. Vine vigor, which is traditionally measured through parameters like trunk cross-sectional area, average shoot length, and pruning weight, is reported to have a considerable effect on fruit yield and quality. ${ }^{23-25}$ The three platforms mainly used in remote sensing are satellites, aircraft, and unmanned aerial vehicles (UAVs) (Figure 1), with different application methods and types of sensors.

\section{Satellite}

Satellites have been used in precision farming for over 40 years, when Landsat 1 was launched into orbit in 1972. It was equipped with a multispectral sensor and provided a spatial resolution of $80 \mathrm{~m}$ per pixel with revisit intervals of approximately 18 days. Landsat 5 was launched in 1984 and collected imagery in the blue, green, red, near-infrared, and thermal bands at a spatial resolution of $30 \mathrm{~m}$. The first application of remote sensing in precision agriculture occurred when Landsat imagery of bare soil was used to estimate spatial patterns in soil organic matter content. ${ }^{26,27}$ In the meantime, there were several ongoing efforts to design higher spatial resolution satellite imaging systems with quicker revisit cycles. The spatial resolution of imaging systems has improved from $80 \mathrm{~m}$ with Landsat to sub-meter resolution with GeoEye and WorldView, and the frequency has improved from 18 days to 1 day with new satellite platforms, with significant advances in sensor performances. 


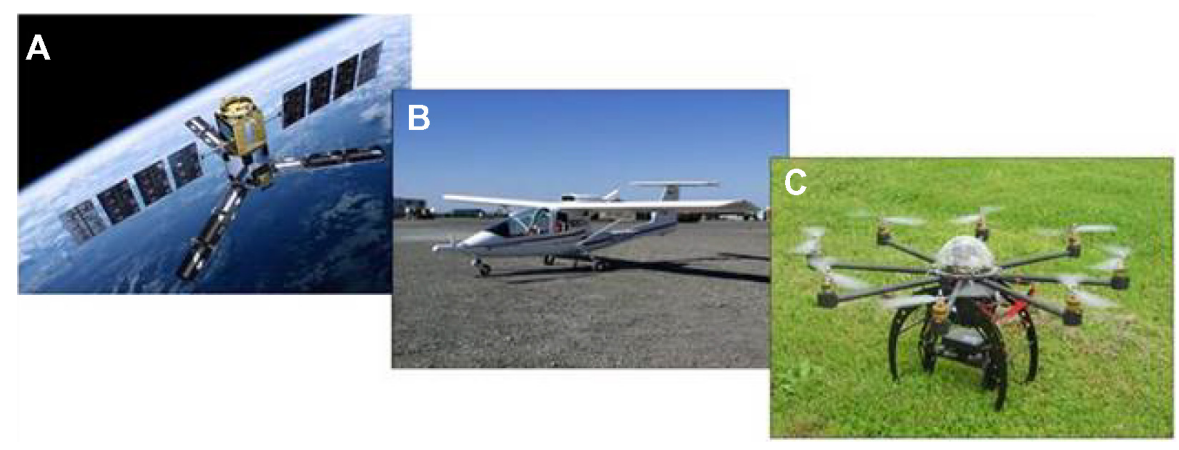

Figure I Remote sensing platforms employed in precision farming. Notes: (A) Satellite. (B) Airborne. (C) Unmanned aerial vehicle.

The latest satellite, WorldView 3, successfully launched in August 2014, is even capable of providing resolutions of $0.30 \mathrm{~m}$ in visible spectra, $1.30 \mathrm{~m}$ in multispectral, and $3.70 \mathrm{~m}$ in short-wave infrared, with a revisit frequency between 1 and 4 days. The use of satellites in remote sensing therefore has great potential, but the spatial resolutions are not sufficient for precision viticulture due to the narrow vine spacing. Another limitation is the temporal resolution, and cloud cover that can occur at the time the satellite passes. ${ }^{28,29}$ The costs of the images are only sustainable on large areas: given the size of a single image, not less than 50 ha.

\section{Aircraft}

Aircraft allow ground monitoring with wide flight range and high payload in terms of weight and dimensions, thus providing the ability to manage a large number of sensors. The aircraft bypasses some limitations of the satellite application by programming the image time acquisition and providing higher ground resolution, depending on the flying altitude. However, the reduced flexibility of the time acquisition, due to the rigid schedule of flight planning and high operational costs, makes it economically viable only on areas of more than 10 ha. An example is the Sky Arrow 650 TC/P68, an aircraft built entirely in carbon and Kevlar, equipped with a 100 HP Rotax engine, with a flight range of about 6 hours. It is a flexible aircraft, which can take off from and land on airports and airfields with a runway length of only $500 \mathrm{~m}$.

\section{UAV}

Technological development in the field of automation has provided precision viticulture with a new solution for remote monitoring, UAVs. These fixed or rotary wing platforms are capable of flying autonomously. They are sometimes also improperly called "drones", due to their monotonous low dull sound like the buzzing of a male bee. UAVs can be remote controlled at visual range by a pilot on the ground, or fly autonomously to a user-defined set of waypoints, by means a complex system of flight control sensors (gyros, magnetic compass, GPS, pressure sensor, and triaxial accelerometers) controlled by a microprocessor. These platforms can be equipped with a series of sensors, which allow a wide range of monitoring operations to be performed. The peculiarity of UAV application in remote sensing is the high spatial ground resolution (centimeters), and the possibility of highly flexible and timely monitoring, due to reduced planning time. These features make it ideal in vineyards of medium to small size (1-10 ha), especially in areas characterized by high fragmentation due to elevated heterogeneity. Vineyards are a common target of study in wine-producing countries, such as the USA, Spain, France, Italy, and Australia. ${ }^{30-42}$ Despite these positive aspects, UAV platforms have an important limitation in terms of payload weight and operating times. Moreover, the implementation of flight regulations has been demanded by UAV stakeholders to drop the barriers for UAV certification and use for all applications involving a large group of contributing agents and institutions. ${ }^{43} \mathrm{UAV}$ regulations are discussed in European RPAS Steering Group (ERSG) ${ }^{44}$ and Federal Aviation Administration (FAA $)^{45}$ reports, and a comprehensive description of the most recent works is presented by van Blyenburgh ${ }^{46}$ who reports the experiences of different expert groups from several countries around the world.

\section{Remote sensing sensors and applications}

Applications of remote sensing in precision viticulture are focused mainly on reflectance spectroscopy, an optical technique based on reflectance measurement of the incident electromagnetic radiation at different wavelengths, in particular in the visible region $(400-700 \mathrm{~nm})$, near infrared $(700-1,300 \mathrm{~nm})$, and thermal infrared $(7,500-15,000 \mathrm{~nm})$. The relationship between the intensity of the reflected and incident radiant flux is specific to each type of surface. The spectral reflectance of a body, such as a crop or soil, is 
called the "spectral signature", and is represented on an XY graph, with the reflectance value on the ordinate and the wavelength of the spectrum on the abscissa.

The most common classes of sensors are capable of detecting an alteration of transpiration or photosynthetic activity on the leaf surface. Thermal sensors are used to remotely measure leaf temperature, which increases when water stress conditions occur, and is followed by stomatal closure, which reduces the water loss and at the same time interrupts the cooling effect of evapotranspiration. Alterations in photosynthetic activity are linked to the nutritional status, health, and vigor of the plants, and can be detected with multispectral and hyperspectral sensors. Leaf reflectance is influenced by different factors in specific regions of the spectra: in the visible by the photosynthetic pigments, such as chlorophyll a, chlorophyll b, and carotenoids; in the near infrared by the structure of the leaves (size and distribution of air and water within the canopy); and in the infrared by the presence of water and biochemical substances, such as lignin, cellulose, starch, protein, and nitrogen.

Satellite and aerial images are frequently used to estimate spatial patterns in crop biomass and yield, using vegetation indices such as the NDVI. Correlation of these indices with structural or physiological characteristics of the vine is well studied. NDVI can be related with different factors, such as the LAI, the presence of nutrient deficiencies, water stress status, or health status, while the narrow-band hyperspectral vegetation indices are sensitive to chlorophyll content. ${ }^{47-53}$

Hyperspectral remote sensing provides a powerful insight into the spectral response of soils and vegetated surfaces, collecting reflectance data over a wide spectral range at high resolution (typically $10 \mathrm{~nm}$ ), while multispectral sensors acquire reflectance data in a reduced spectrum range focused on the blue, green, red, and near-infrared regions, with less resolution (at least $40 \mathrm{~nm}$ wide). Another field of application is the study of the canopy structure and biomass by light detection and ranging (LiDAR) systems, a remote sensing technology that measures distance by illuminating a target with a laser and analyzing the reflected light. Figure 2 shows some of the newest remote sensing sensors used in precision viticulture.

\section{Proximal sensing}

Within proximal sensing applications, there are many tools available for continuous measurements carried by moving vehicles, or instruments for precise ground observations made by an operator.

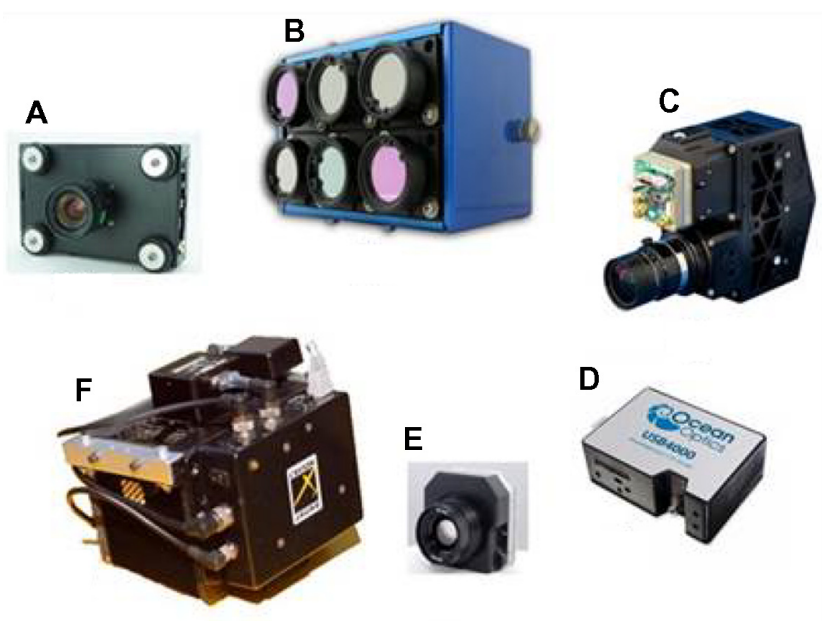

Figure 2 Some kinds of sensors developed ad hoc for monitoring applications for unmanned aerial vehicle platforms.

Notes: (A) Three-band multispectral camera Tetracam ADC-Lite. (B) Sixband multispectral camera Tetracam Mini-MCA. (C) Micro-Hyperspec VNIR hyperspectral camera. (D) Ocean Optics USB4000 spectrometer. (E) FLIR TAU II. (F) YellowScan LiDAR.

Abbreviation: LiDAR, light detection and ranging.

\section{Wireless sensor network}

Wireless sensor network (WSN) technologies provide a useful and efficient tool for remote and real-time monitoring of important variables involved in grape production, processing the data and transmitting the required information to the users. A WSN is a network of peripheral nodes consisting of a sensor board equipped with sensors and a wireless module for data transmission from nodes to a base station, where the data are stored and accessible to the end user. The nodes are energy independent and are installed in areas representative of the vineyard variability, which can be identified with information provided by a vigor map (Figure 3). A comprehensive review on the state of the art of WSN in agriculture and the food industry was written by Ruiz-Garcia et al. ${ }^{54}$ With regard to viticulture, Burrell et $\mathrm{a}^{55}$ described WSN applications and configurations for

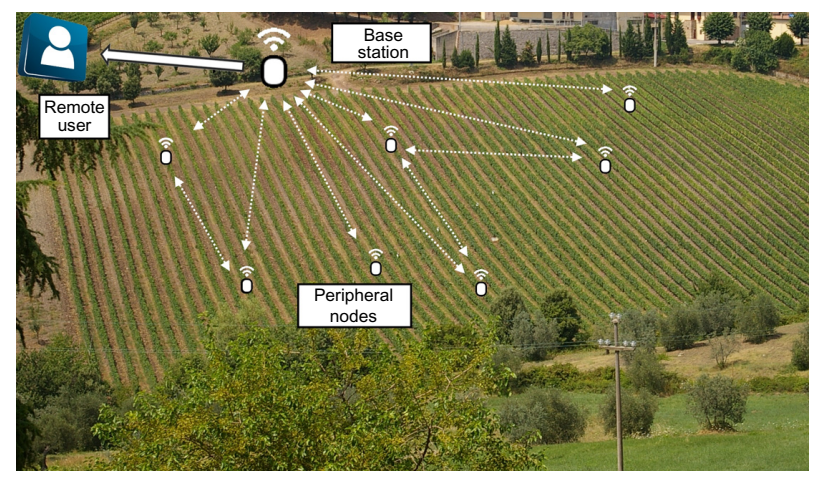

Figure 3 Wireless sensor network architecture deployed in a vineyard at Azienda Agricola Castello di Brolio, Siena, Italy. 
different purposes within the vineyard, while Beckwith et $\mathrm{al}^{56}$ implemented a WSN consisting of 65 motes that collected temperature measurements in a vineyard over 1 month. Matese et $\mathrm{al}^{57}$ proposed a wireless sensor application in precision viticulture, which enables site-specific microclimate monitoring for different vigor areas of the vineyard. In recent years, the advent of low-cost and opensource technologies has led to their wide diffusion in the scientific community. ${ }^{58,59}$ The possibilities afforded by an open-source hardware system, the most famous example being the Arduino project, include the rapid prototyping of information communication technology systems where circuit models are licensed under Creative Commons and the source codes are publicly available and customizable by the user. ${ }^{60}$ This leads to a coordinated development of hardware and software solutions, with ample and effective support from network communities, therefore a wide range of ready-to-use software applications is available on the Web, shortening development times.

At the same time, the evolving technology provides solutions that are increasingly efficient in terms of minimal size, low cost and power supply, and improved power transmission, which allow greater distances to be covered with reduced consumption. The primary application of WSNs is the acquisition of micrometeorological parameters at vine canopy and soil level. In the last decade, the continuous innovation process has allowed the development of new kinds of sensors for plant physiology monitoring, such as dendrometers and sap-flow sensors, for the continuous measurement of plant water status for irrigation scheduling. Figure 4 presents some sensors employed in WSN.

\section{Soil monitoring}

An important application of innovative techniques in precision viticulture is the proximal monitoring of soil variability, which includes the use of a wide range of sensors. Measurement of the apparent electrical conductivity of the soil can be detected by mobile platforms equipped with soil electromagnetic sensors and GPS for continuous measures. ${ }^{61,62}$ It is a parameter strongly correlated with many soil properties, such as texture and depth, water retention capacity, organic matter content, and salinity. The sensors used for this type of measurement are either invasive electrical resistivity or noninvasive electromagnetic induction sensors. The first type (electrical resistivity) are used to control the resistivity, and therefore conductivity, of a given volume of soil, generating electrical currents and subsequently measuring the potential differences. Among the commercial systems available, the Veris 3100 (Veris Technologies Inc, Salina, KS, USA) and the Automatic Resistivity Profiling system (ARP) (Geocarta Ltd, Paris, France) are the most common. The operating principle of the electromagnetic induction sensors involves the generation of a magnetic field that induces electrical current in the ground, which in turn creates a second magnetic field proportional to the conductivity of the soil that is measured by the sensor. Some devices on the market are the DualEM (DualEM, Milton, ON, Canada) and EM-31 and EM-38 (Geonics Ltd, Mississauga, ON, Canada). There are also newly developed sensors for mobile platform

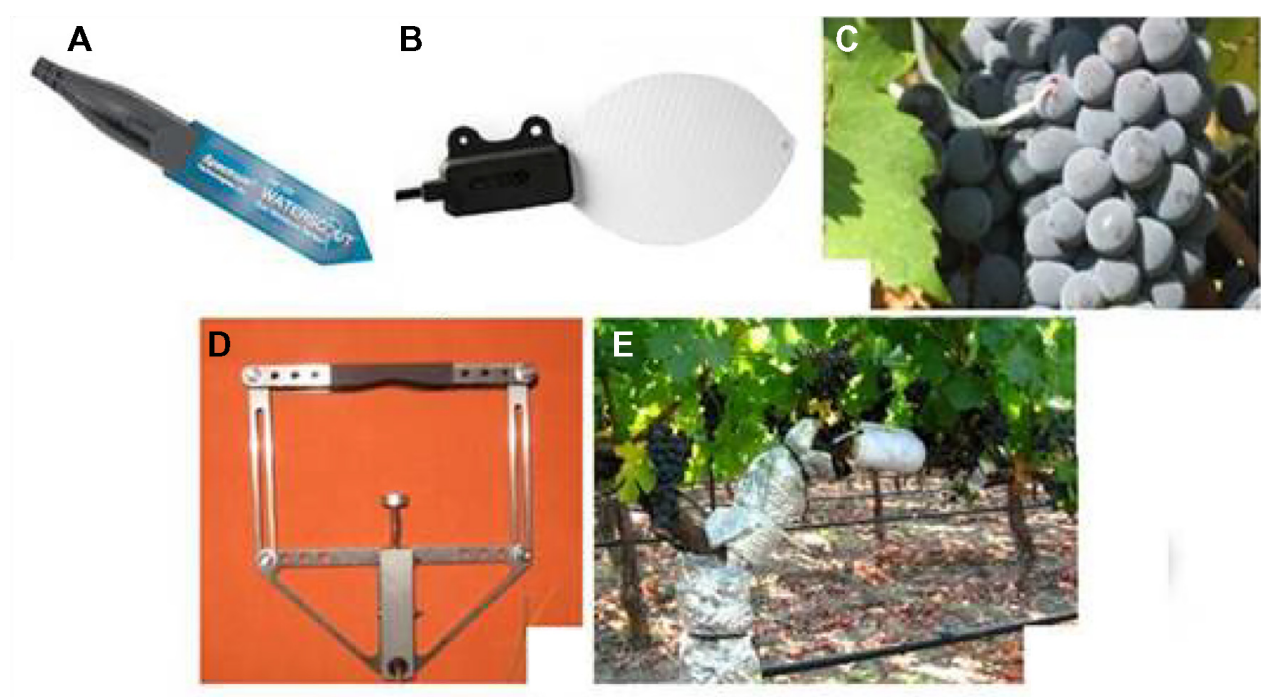

Figure 4 Some sensors employed in wireless sensor networks for proximal sensing in vineyards.

Notes: (A) Soil moisture (Spectrum Technologies Aurora, IL, USA). (B) Leaf wetness (Decagon Devices Inc., Pullman, WA, USA). (C) Grape temperature and (D) dendrometer (GMR Strumenti SAS Scandicci, Italy). (E) Sap flow (Fruition Sciences Inc., Montpellier, France). 
applications, for the measurement of $\mathrm{pH}$, ionic nitrogen, and potassium content, for the measurement in near-infrared and mid-infrared spectra, ground penetrating radar, and radiometers. The soil proprieties play an important role in vine growing, so knowing the spatial variability of soil characteristics within a vineyard allows improved understanding of vine physiological response variability.

\section{Crop monitoring}

Many systems have been developed for monitoring vineyards, which provide a high-resolution screening of the canopy side across the row coupled with a GPS system for data georeferencing. In relation to crop sensors, Zhang et al point out various possibilities. ${ }^{63}$ One example of these sensors is GrapeSense (Lincoln Ventures Ltd, Hamilton, New Zealand), which captures a high-frequency digital image of the canopy side, collecting information on the height and texture of the vines along the row. Other systems are based on multispectral sensors like GreenSeeker ${ }^{\circledR}$ (NTECH Industries Inc, Ukiah, CA, USA) and the Cropcircle (Netherlands Scientific Inc, Lincoln, NE, USA), which supply information for vegetation indices calculation, strongly correlated with the vertical LAI and the leaves' layer density. These sensors are designed to be mounted on machines and tractors (Figure 5), allowing the acquisition of spatial data during the daily vineyard management. Another solution in continuous development is the use of LiDAR sensors, which can provide a georeferenced $3 \mathrm{D}$ reconstruction of each single plant and generate spatial variability maps referring to the volumetric size of the canopy, directly correlated with the LAI. Thanks to these proximal monitoring systems, it becomes possible to analyze the spatial variability with higher resolution than provided remotely.

\section{Yield and quality monitoring}

Many systems have been developed to obtain georeferenced yield information, especially integrated on mechanical harvesters. Varieties of solutions are now available on the market such as HarvestMaster Sensor System HM570 (Juniper Systems Inc., Logan, UT, USA), Canlink Grape Yield Monitor 3000GRM (Farmscan, Bentley, WA, Australia), and Advanced Technology and Viticulture (ATV) (Advanced Technology Viticulture, Joslin, SA, Australia). The HM570 system operating principle is based on a volumetric grape

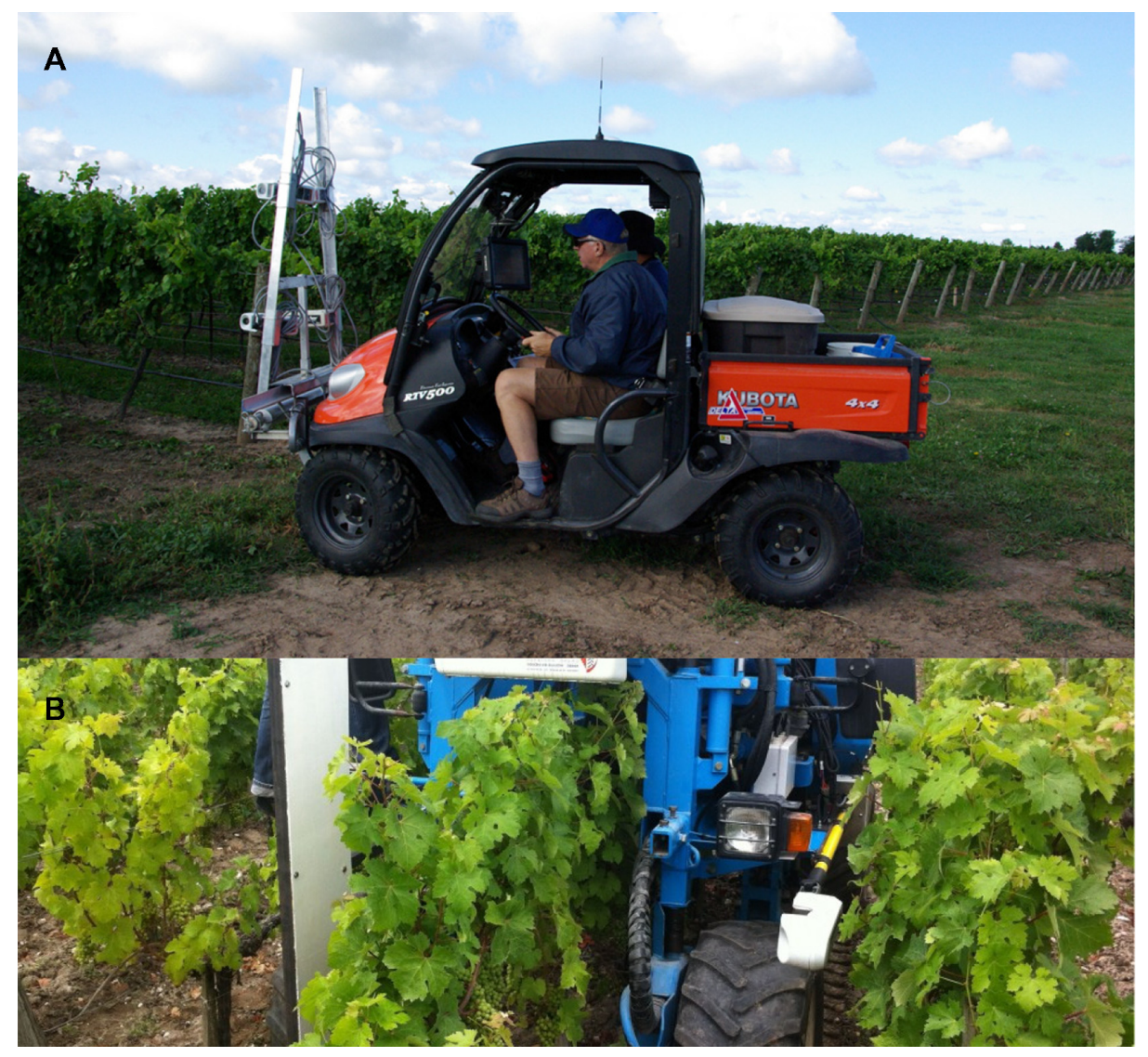

Figure 5 The Trimble ${ }^{\circledR}$ GreenSeeker ${ }^{\circledast}$ multispectral sensor for canopy monitoring, carried on a quad (Practical Precision Inc., Tavistock, Canada) (A) or tractor (Avidorhightech SA, Le Mont-Pèlerin, Switzerland) (B). 
measurement on the discharge conveyor belt of the harvester; 3000GRM and ATV systems perform a direct measurement of the transported grape weight by means of load cells. These tools give the farmer the ability to map the vineyard productivity with a resolution never previously achieved (Figure 6). The yield maps realized with these sensors represent an excellent tool to verify the effectiveness of management practices applied in the vineyard.

Nondestructive monitoring of grape quality parameters is based on optical sensors designed as "hand devices", instruments carried by an operator, used for proximal georeferenced measurements (Figure 7). Among the most important devices available, the Spectron (Pellenc SA, Pertuis Cedex, France) is a portable spectrophotometer with integrated GPS, designed to monitor grape maturation through nondestructive measurement of parameters related to grape quality, such as the sugar, acidity, and anthocyanin concentration and water contents. The Multiplex (Force-A, Orsay Cedex, France) is a portable optical sensor that uses fluorescence to quantify polyphenols and chlorophyll content, with georeferenced noncontact measurements both on target leaves and grapes. ${ }^{64}$ The processing of the acquired data allows indices to be obtained relating to the concentration in flavonols, anthocyanins, chlorophyll, and nitrogen nutrition. Given its technical specifications, this tool has also been used on mobile ground vehicles.

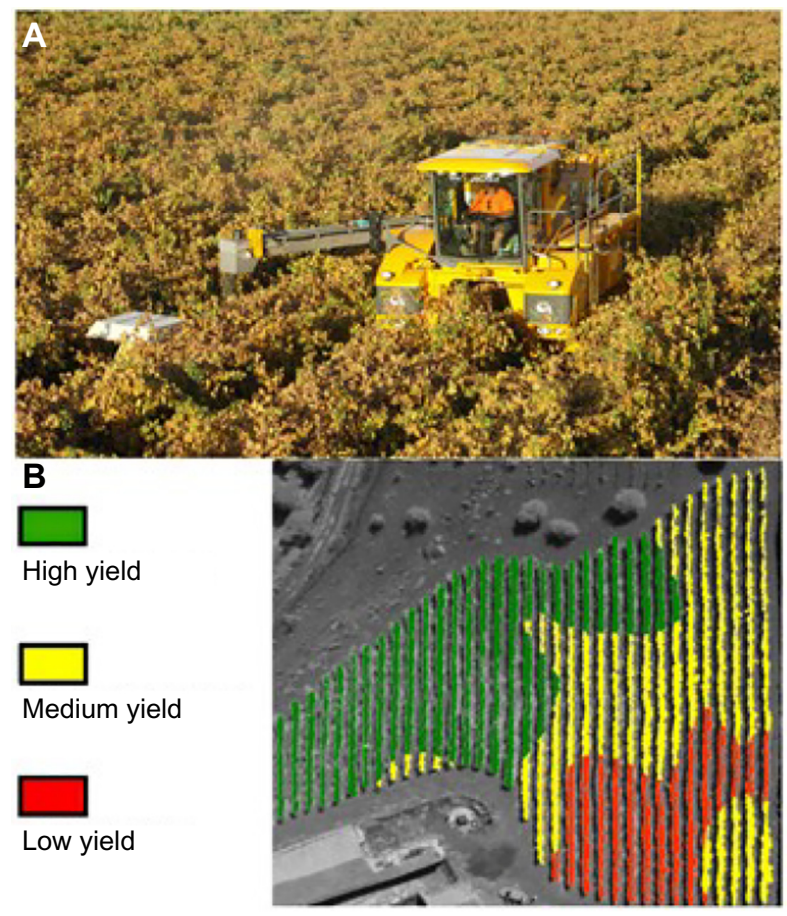

Figure 6 Harvester (GREGOIRE Group, Cognac Cedex, France) equipped with a georeferenced yield monitoring system (A) and a yield map of the vineyard (B).

\section{VRTs and agbots}

VRT in precision viticulture allows agronomic management to be differentiated and the inputs dosed in time and space. This technology uses software that can combine the position information, obtained by a GPS module, with prescription maps generated for each specific operation. ${ }^{65}$ The agronomic inputs will no longer be applied as average quantities per hectare, but according to the real needs of the vines derived from the vineyard heterogeneity.

The concurrent development of standard electronic communication in agricultural machinery has facilitated the connection between tractors and equipment. Considerable efforts have been made to develop international standards to regulate the communication protocols and exchange of information between sensors, actuators, and software from different manufacturers. Research conducted on VRT has explored many application solutions, including the differentiated distribution of fertilizers and pesticides and pruning methods. ${ }^{66,67}$ The key factors of the variable-rate strategy potential are based on the development of innovative technologies in the field of vegetation monitoring and high-performance atomization systems. The implementation of site-specific vineyard management aims to abandon the concept of the vineyard as a territorial unit, and suggests a parcel and even sub-parcel management level. With engineering development, in particular in the field of satellite navigation systems, VRT will become more accurate and easier to use, with lower costs.

\section{VRT}

Modern agricultural machines utilize automation technologies both to control the movement within the vineyard, in terms of speed and direction of travel and steering angle, and to manage the agronomic operations. Advanced board technology makes it possible to have an automatic guidance system based on the use of GPS and proximity sensors. ${ }^{68}$ At the same time, tractors have been engineered to perform site-specific operations autonomously without human intervention, thanks to the interpretation of prescription maps made with monitoring sensors mounted on board, which can monitor the plant status during the progress along the row, interpreting information and managing operations in real time. There are many commercial solutions for VRT in vineyards (Figure 8).

This technology meets the current needs of the food industry, ensuring adequate productivity and profitability in the vineyard. The resulting benefits are a substantial reduction of the work and speeded-up operations. The guidance systems can reduce operating stress, while the VRT provides 


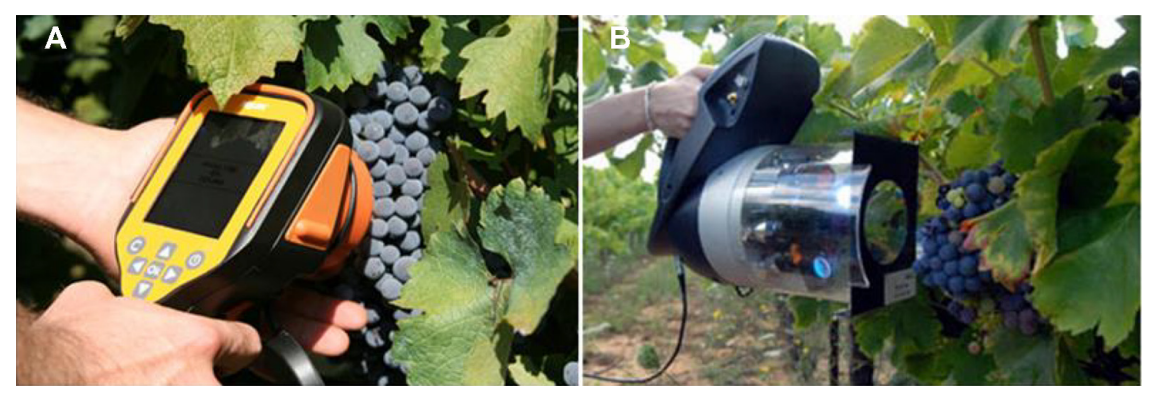

Figure 7 Spectron (A) and Multiplex (B) hand-device sensors for grape quality proximal monitoring, which allows quality maps to be realized.

a rational use of agronomic inputs, with direct impact on costs, quality, and environmental sustainability.

\section{Robotics}

The use of robotics in precision viticulture is still at a prototype stage, but many projects are already in the final stage of development, and some have already been put on the market.
Professor Simon Blackmore, a leading expert in precision agriculture, told at the 2014 Oxford Farming Conference in the UK that his vision was for "farming with robots in 2050", and that "farmbots" or "agbots" are the future of agriculture ${ }^{69}$ If, in recent years, there has been an important effort of innovative technologies in agriculture, the coming years will see an exponential increase with higher-performance solutions and
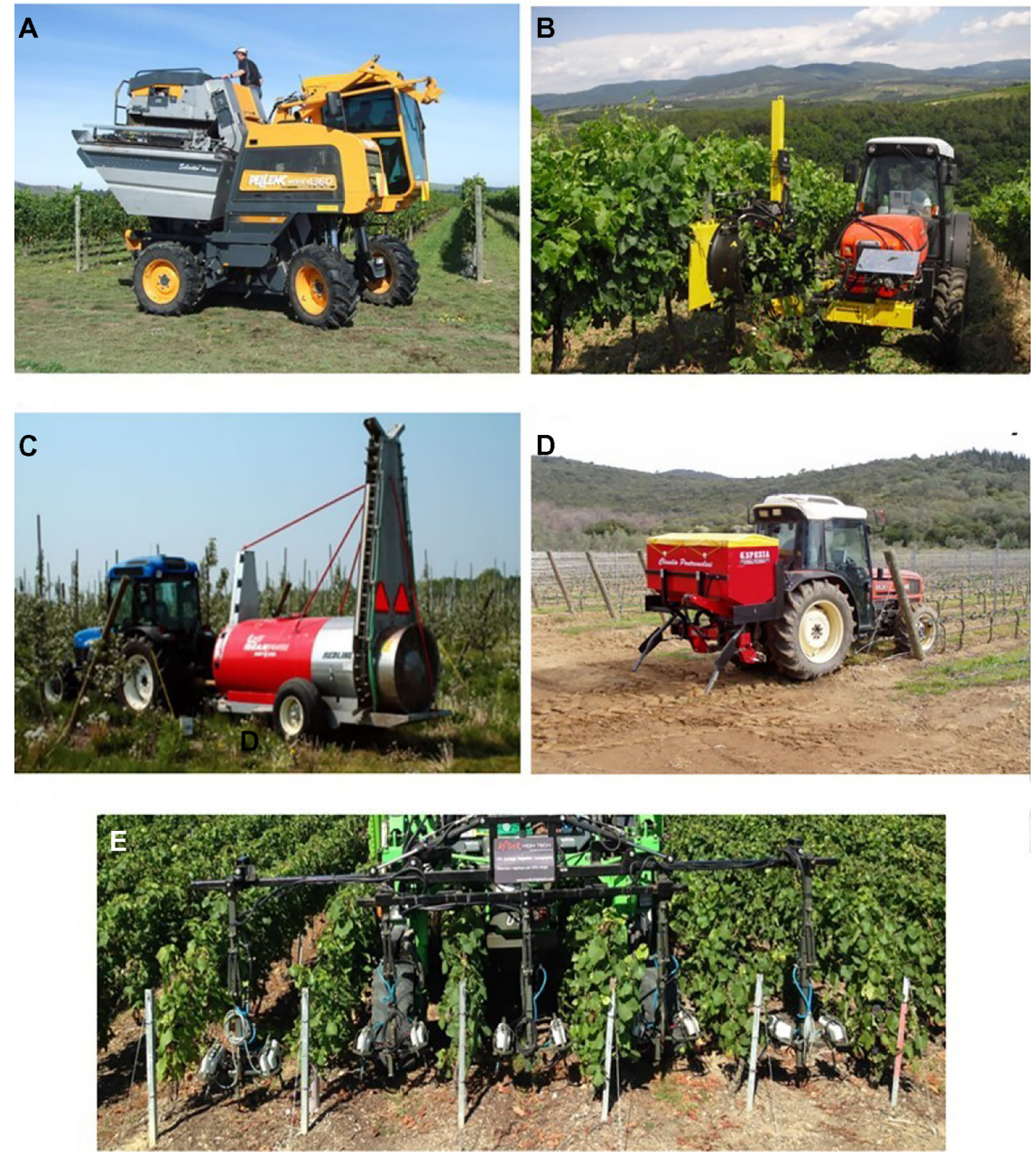

Figure 8 Some automated commercial solutions used in precision viticulture.

Notes: (A) Pellenc Australia 600 LM SP selective harvester. (B) Tecnovit Mod. II I S VRT variable-rate leaf stripper. (C) Durand-Wayland SmartSpray selective atomizer with ultrasound sensors. (D) Tecnovit Mod. VRT 150 variable-rate fertilizer spreader. (E) GreenSeeker ${ }^{\circledR}$ vigor monitoring system for treatments at variable rate. 
reduced costs. Automation and robotics will be accessible to small businesses, becoming widespread, but we must not forget that all this technology for monitoring and intervention is of no use without the support of the farmer's experience.

A review follows of the robotic innovations for precision viticulture. The VineRobot project coordinated by Televitis group, at the University of La Rioja in Logroño, La Rioja, Spain, has received more than $€ 2$ million financing by the European Union. ${ }^{70}$ The goal of the project is the development of a new agricultural robot, equipped with noninvasive sensing technologies, such as sensors, fluorescence, multispectral, RGB for machine vision, thermal infrared, and GPS. The system is designed to perform a proximal monitoring of various critical parameters such as yield, vigor, water stress, and quality of the grapes, and provides a tool for decision support to the grower to improve the management of the vineyard (Figure 9A).

The VINBOT project exploits the technology proposed by the Spanish Robotnik Automation Company. ${ }^{71}$ It has developed a robotic platform with open-source software. The system is equipped with sensors for $3 \mathrm{D}$ reconstruction of the leaf curtain, and multispectral cameras for vine vigor, to provide important information such as the estimation of productivity. The robot acquires data at an operating speed that can monitor a surface of 1 ha per hour; it is capable of moving on slopes of up to $45^{\circ}$ and is powered by an electric motor with a range of 8 hours a day (Figure 9B).

The Wall-Ye robot is a product developed for vineyard monitoring by Christophe Millot. ${ }^{72}$ It can move independently along the rows, acquiring data on each vine, and producing a very highly detailed vineyard map. Thanks to a monitoring system based on many optical sensors, this robot cannot only perform correct displacements within the vineyard, but also carry out precision pruning, respecting the specific structure of each individual vine. Wall-Ye has an autonomy of 12 hours and can prune about 600 plants per day. It can also be monitored remotely by means of an application developed for the iPad. Thirty have already been sold to French winegrowers, at a market price of around $€ 25,000$ (Figure 9C).

Ben-Gurion University of the Negev, in Beer Sheva, Israel, developed a prototype designed for foliar applications. ${ }^{73}$ The robot, called VineGuard, can move within the vineyard using a complex set of sensors, with a movement system optimized for rough terrain. In addition to this application, a robotic arm designed for grape harvesting is in development, using artificial intelligence to guide the robot in a series of operations, such as localization, assessment of the maturation state, and selection and detachment of the grapes from the vine (Figure 9D).

Vitirover is the result of a project conceived and produced by Xavier David Beaulieu, owner of Chateau Coutet (Saint Emilion, France), and received an award at the Grand Prix of Innovation in 2012 at the salon Vinitech-Sifel. ${ }^{74}$ This little robot is able to cut the grass up to a distance of $2-3 \mathrm{~cm}$ from the base of the vine, in full respect of the plant, ensuring a cutting height of between 4 and $10 \mathrm{~cm}$. The robot has four drive wheels that allow it to work in steep vineyards up to a maximum gradient of $15 \%$. The power system is completely

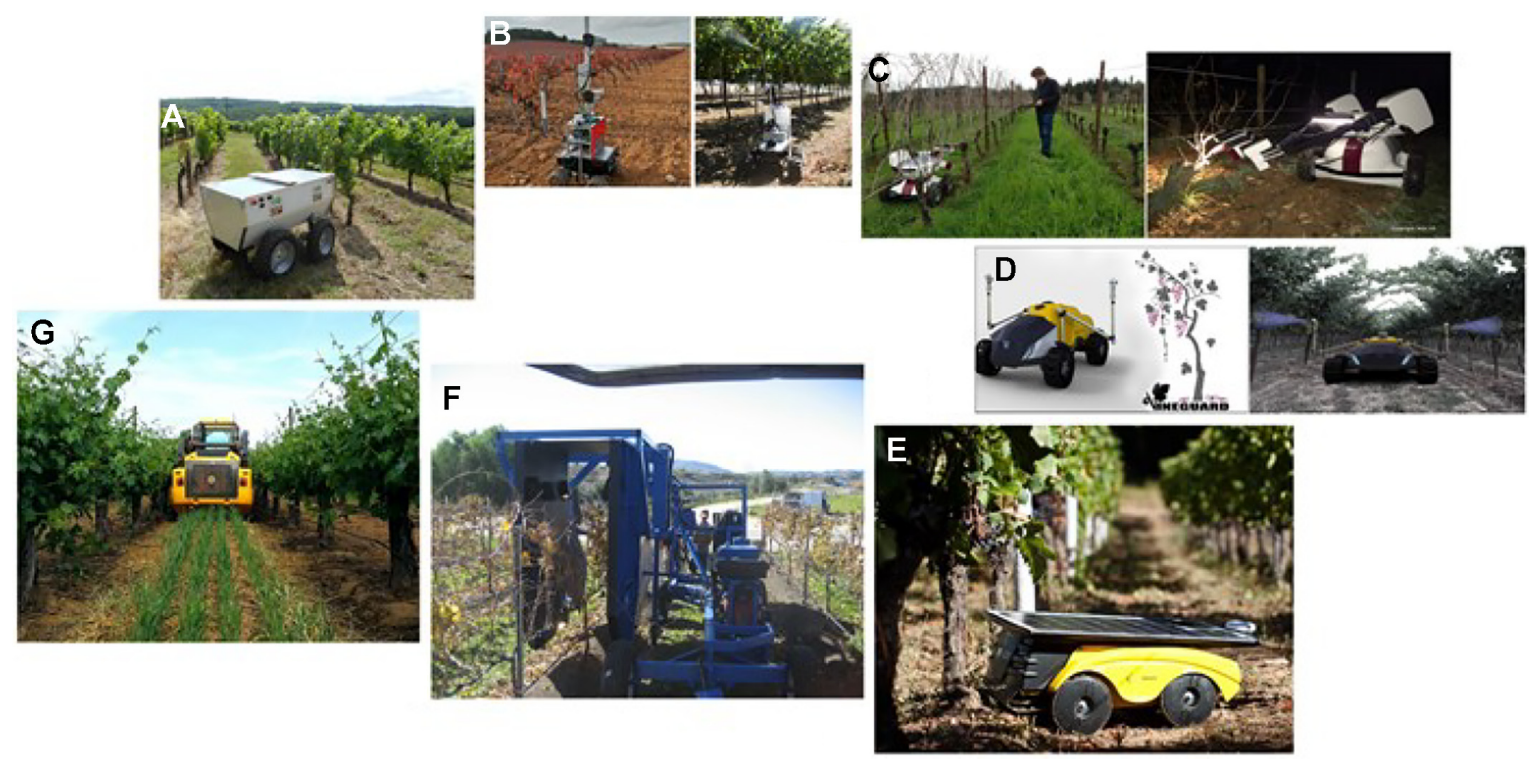

Figure 9 Some robot prototypes and commercial solutions for precision viticulture.

Notes: (A) VineRobot. (B) VINBOT. (C) Wall-Ye. (D) VineGuard. (E) Vitirover. (F) Vision Robotics Corporation (VRC) robot. (G) Forge Robotic Platform. 
self-sufficient thanks to a solar panel; however, the operating speed is low $(500 \mathrm{~m} / \mathrm{h})$, so about 100 hours of work is needed to cover 1 ha of vineyard. The robot works independently on the basis of GPS coordinates, but can also be controlled by computer or smartphone thanks to a simple application compatible with iPhone, BlackBerry, and Android. Although the machine is able to work in a constant way, the time necessary to treat a single hectare remains high, and is therefore also a function of the relatively low cost (about $€ 5,000$ ). The manufacturers recommend the use of multiple units for efficient vineyard management (Figure 9E).

The American company Vision Robotics Corporation (VRC) has developed a prototype able to perform a precision pruning, by means of optical sensors that perform a $3 \mathrm{D}$ reconstruction of the vine structure. ${ }^{75}$ The robot identifies the points of intervention according to the specifications provided by the harvester, and carries out very high-detail pruning cuts by means of two hydraulic shears. The prototype is still in an experimental phase, but the final product is expected to be on the market in 2016 at a base price of about $€ 120,000$ (Figure 9F).

A robot tractor prototype has been developed by Autonomous Solutions (ASI). ${ }^{76}$ The Forge Robotic Platform can be driven by remote or be completely autonomous, but will also be available in a cab version for transporting the operator on board. It is a real tractor capable of supporting agricultural tools commonly used in vineyard management. The testing phase of this prototype is nearly over. It is intended to be marketed by the end of 2015, with a price ranging between $€ 60,000$ and $€ 120,000$, depending on the configuration (Figure 9G).

\section{Conclusion}

The aim of this review is to report the state of the art of technologies in the field of precision viticulture. In recent years, these technologies had rapid development and greater applicability due to lower costs, ease of use, and versatility. In general, the application advantage of these innovative solutions is a cost reduction in crop management, through improving crop quality and yield production, process traceability and environmental sustainability with a rational use of chemical inputs.

The rapid innovation in proximal sensing technologies involve an optimization of Decision Support System (DSS) and thus make possible the implementation of rapid intervention strategies. However, it will be necessary to choose the best remote sensing platform for each kind of application. Even if satellite and aircraft are excellent tools for producing prescription maps for variable-rate applications, satellite already has limitations due to low resolutions for precision viticulture, and aircraft imply very high operational costs. At the same time, the UAV platform presents a high ground resolution, great flexibility of use and timely intervention, but it is economically feasible only for small areas (about $10 \mathrm{ha}$ ) and experimentation. VRTs are well developed and widely used, especially in chemical applications.

Currently, remote and proximal monitoring technologies and variable-rate machinery are applied on a broad basis, while robotics reported in this review are in an experimental stage.

In general, there are issues to overcome before widespread adoption of these technologies can take place, which are related not only to the need to further explore the potential of these tools, but above all to the ability of farms to train technicians capable to understand and properly use this type of technology.

\section{Acknowledgments}

The authors are grateful to Alessandro Zaldei, Francesco Sabatini, Tiziana De Filippis, Leandro Rocchi (IBIMET-CNR), Alberto Palliotti (UNIPG), Filippo Rossi (GMR Strumenti SAS), Gianfranco Soldera (Agricola Case Basse), and Massimiliano Biagi (Barone Ricasoli). This work was supported in part by a grant from the Italian Ministry of Economy and Finance to the National Research Council for the project "Innovazione e Sviluppo del Mezzogiorno-Conoscenze Integrate per Sostenibilita" ed Innovazione del Made in Italy Agroalimentare-Legge n 191/2009 and by the Italian MIUR (Progetto Premiale AQUA to CNR).

\section{Disclosure}

The authors report no conflicts of interest in this work.

\section{References}

1. Bramley RGV, Proffitt APB, Corner RJ, Evans TD. Variation in grape yield and soil depth in two contrasting Australian vineyards. Australian and New Zealand Second Joint Soils Conference; December 3-8, 2000; Lincoln, New Zealand. 29-30.

2. Bramley R, Pearse B, Chamberlain P. Being profitable precisely - a case study of precision viticulture from Margaret River. Australian and New Zealand Grapegrower and Winemaker. 2003;473a:84-87.

3. Bramley RGV. Progress in the development of precision viticulture variation in yield, quality and soil properties in contrasting Australian vineyards. In: Currie LD, Loganathan P, editors. Precision Tools for Improving Land Management: Proceedings of the Workshop held by the Fertilizer and Lime Research Centre in Conjunction with the NZ Centre for Precision Agriculture at Massey University, Palmerston North, New Zealand, 14-15 February, 2001:25-43.

4. Bramley RGV, Williams SK. A protocol for winegrape yield maps. Proceedings of the 3rd European Conference on Precision Agriculture. June 18-21, 2001; Montpellier, France. 773-778. 
5. Bramley RGV, Lamb DW. Making sense of vineyard variability in Australia. Proceedings IX Congreso Latinoamericano de Viticultura y Enología. November 24-28, 2003; Santiago, Chile. 35-54.

6. Bramley RGV, Hamilton RP. Understanding variability in winegrape production systems. 1. Within vineyard variation in yield over several vintages. Australian Journal of Grape and Wine Research. 2004;10: 32-45.

7. Taylor JA. Digital Terroirs and Precision Viticulture: Investigations into the Application of Information Technology in Australian Vineyards [doctoral thesis]. Sydney: University of Sydney; 2004.

8. Tisseyre B, Mazzoni C, Ardoin N, Clipet C. Yield and harvest quality measurement in precision viticulture - application for a selective vintage. Proceedings of the 3rd European Conference on Precision Agriculture. June 18-21, 2001; Montpellier, France. 133-138.

9. Arnó J, Bordes X, Ribes-Dasi M, Blanco R, Rosell JR, Esteve J. Obtaining grape yield maps and analysis of within-field variability in Raimat (Spain). Proceedings of the 5th European Conference on Precision Agriculture June 8-11, 2005; Uppsala, Sweden. 899-906.

10. Arnó J, Martínez-Casasnovas JA, Blanco R, Bordes X, Esteve J. Viticultura de precisión en Raimat (Lleida): experiencias durante el período 2002-2004 [Precision viticulture in Raimat (Lleida): experiences during the period 2002-2004]. ACE: Revista de Enología. 2005;64. Available from http://www.acenologia.com/ciencia73_01.htm [April 20, 2008]. Spanish.

11. Arnó J. Variabilidad Intraparcelaria en Viña y uso de Sensores Láser en Viticultura de Precisión [doctoral thesis]. [Laser sensor in Precision Viticulture to describe intra-field variability in the vineyard] Lleida: University of Lleida; 2008. Spanish.

12. Penn C. Grape growers gravitating toward space age technologies. In Wine Business Monthly, Wine Communications Group, Sonoma, CA, USA. 1999.

13. Carothers J. Imagery technology meets vineyard management. Practical Winery and Vineyard. 2000;21(1):54-62.

14. Aho JE. NASA providing new perspectives on vineyard management. Vineyard and Winery Management. 2002;28(4):74-77.

15. Bramley R. Smarter thinking on soil survey. Australian and New Zealand Wine Industry Journal. 2003;18(3):88-94. Available from http://iwrdb. org/cgi-bin/koha/opac-detail.pl?biblionumber $=30800$.

16. Smart RE. Principles of grapevine canopy management microclimate manipulation with implications for yield and quality. American Journal of Enology and Viticulture. 1985;36(3):230-239. Available from http:// www.ajevonline.org/content/36/3/230.full.pdf.

17. Proffit T, Bramley R, Lamb D, Winter E. Precision Viticulture - A New Era in Vineyard Management and Wine Production. Winetitles Pty Ltd., Ashford, South Australia; 2006:1-90.

18. Vieri M, Lisci R, Rimediotti M, Sarri D. The innovative RHEA airblast sprayer for tree crop treatment. Proceedings of the 1st International Conference on Robotics and Associated High-Technologies and Equipment for Agriculture (RHEA'12), Pisa, Italy, Sept 2012. 93-98.

19. Hall A, Lamb DW, Holzapfel B, Louis J. Optical remote sensing applications in viticulture - a review. Australian Journal of Grape and Wine Research. 2002;8:36-47.

20. Rouse JW, Haas RH, Schell JA, Deering DW. Monitoring vegetation systems in the Great Plains with ERTS. In: Fraden SC, Marcanti EP, Becker MA, editors. 3rd ERTS-1 Symposium. December 10-14, 1973; NASA SP-351, Washington DC, U S A. 309-317. ftp://landsat-legacy. gsfc.nasa.gov/outgoing/documents/LL-36976330531.pdf.

21. Zarco-Tejada PJ, Miller JR, Mohammed GH, Noland TL, Sampson PH Scaling-up and model inversion methods with narrow-band optical indices for chlorophyll content estimation in closed forest canopies with hyperspectral data. IEEE Transactions on Geoscience and Remote Sensing. 2001;39:1491-1507.

22. Tisseyre B, Ardoin N, Sevila F. Precision viticulture: precise location and vigour mapping aspects. Proceedings of the 2nd European Conference on Precision Agriculture; 1999; Odense, Denmark. 319-330.

23. Dry PR. Canopy management for fruitfulness. Australian Journal of Grape and Wine Research. 2000;6:109-115.
24. Haselgrove L, Botting D, van Heeswijck R, et al. Canopy microclimate and berry composition: the effect of bunch exposure on the phenolic composition of Vitis vinifera L cv Shiraz grape berries. Australian Journal of Grape and Wine Research. 2000;6:141-149.

25. Petrie PR, Trought MCT, Howell GS. Growth and dry matter partitioning of Pinot Noir (Vitis vinifera $\mathrm{L}$ ) in relation to leaf area and crop load. Australian Journal of Grape and Wine Research. 2000;6: $40-45$.

26. Bhatti AU, Mulla DJ, Frazier BE. Estimation of soil properties and wheat yields on complex eroded hills using geostatistics and thematic mapper images. Remote Sens Environ. 1991;37:181-191.

27. Mulla DJ. Twenty five years of remote sensing in precision agriculture: key advances and remaining knowledge gaps. Biosystems Engineering. 2013;114(4):358-371.

28. Marçal ARS, Cunha M. Vineyard monitoring in Portugal using multisensor satellite images. In: Gomarasca MA, editor. Proceedings of the 27th EARSeL Symposium, Geoinformation in Europe. Rotterdam Millpress; 2007:327-335.

29. Marçal ARS, Gonçalves JA, Gonçalves H, Cunha M. Analysis of the temporal signature of vineyards in Portugal using vegetation. In: Bochenek Z, editor. Proceedings of the 26th EARSeL Symposium, New Developments and Challenges in Remote Sensing. Rotterdam: Millpress; 2007:377-384.

30. Berni J, Zarco-Tejada PJ, Suárez L, Fereres E. Thermal and narrowband multispectral remote sensing for vegetation monitoring from an unmanned aerial vehicle. IEEE Transactions on Geoscience and Remote Sensing. 2009;47:722-738.

31. Johnson LF, Herwitz S, Dunagan S, Lobitz B, Sullivan D, Slye R. Collection of ultra high spatial and spectral resolution image data over California vineyards with a small UAV. In: Proceedings of 2003 International Symposium on Remote Sensing of Environment (ISRSE). November 10-14, 2003; Honolulu, HI, USA. 3-5. East-West Center, International Society for Photogrammetry and Remote Sensing and International Center for Remote Sensing of Environment, editor. International Center for Remote Sensing of Environment 2003.

32. Scholasch T, Dawson T, Bellon-Maurel V, Rubin Y. Role of vapor pressure deficit and soil moisture at different depths on stomatal conductance regulation. Insufficience of midday stem water potential for explaining stomatal conductance (Cabernet-Sauvignon- Napa Valley). Proceedings of the Fruits and Nuts and Vegetable Production Engineering TIC (Frutic05) Conference. 2005; Montpellier, France. 279-288.

33. Gago J, Martorell S, Tomás M, et al. High-resolution aerial thermal imagery for plant water status assessment in vineyards using a multicopter-RPAS. In: Proceedings of 2013 VII Congreso Ibérico de Agroingeniería y Ciencias Hortícolas. Ayuga, F, Masaguer, A, Mariscal Ignacio,Villarroel M, Ruiz-Altisent M, Riquelme F, Correa E, editors. Fundación General de la Universidad Politécnica de Madrid. August 26-29, 2013; Madrid, Spain. 1-6.

34. Baluja J, Diago MP, Balda P, et al. Assessment of vineyard water status variability by thermal and multispectral imagery using an unmanned aerial vehicle (UAV). Irrigation Science. 2012;30:511-522.

35. Zarco-Tejada PJ, Miller JR, Mohammed GH, Noland TL, Sampson PH. Vegetation stress detection through chlorophyll $\mathrm{a}+\mathrm{b}$ estimation and fluorescence effects on hyperspectral imagery. Journal of Environmental Quality. 2002;31(5):1433-1441.

36. Santesteban LG, Tisseyre B, Royo JB, Guillaume S. Is it relevant to consider remote sensing information for targeted plant monitoring? Proceedings of the 7th International Terroir Congress. 2008; Nyon, Suisse. 469-474.

37. Acevedo-Opaz C, Tisseyre B, Guillaume S, Ojeda H. Test of NDVI information for a relevant vineyard zoning related to vine water status. Proceedings of 6th ECPA-European Conference on Precision Agriculture. June 3-6, 2007; Skiathos, Greece. 547-554.

38. Matese A, Primicerio J, Di Gennaro SF, Fiorillo E, Vaccari FP, Genesio L. Development and application of an autonomous and flexible unmanned aerial vehicle for precision viticulture. Acta Horticulturae. 2013;978:63-69. 
39. Lamb DW. The use of qualitative airborne multispectral imaging for managing agricultural crops - a case study in south-eastern Australia. Australian Journal of Experimental Agriculture. 2000;40(5): 725-738.

40. Proffitt APB, Pearse B. Adding value to the wine business precisely: using precision viticulture technology in Margaret River. Australian and New Zealand Grapegrower and Winemaker. 2004;491:40-44. Available from http://dialnet.unirioja.es/servlet/articulo? codigo $=1048626$

41. Lamb DW, Weedon MM, Bramley RGV. Using remote sensing to predict phenolics and colour at harvest in a Cabernet Sauvignon vineyard: timing observations against vine phenology and optimising image resolution. Australian Journal of Grape and Wine Research . 2004;10: 46-54. Available from http://onlinelibrary.wiley.com/doi/10.1111/j.1755-0238.2004. tb00007.x/full. Accessed April 28, 2015.

42. Bramley RGV, Proffitt APB, Hinze CJ, Pearse B, Hamilton RP. Generating benefits from precision viticulture through differential harvest. Proceedings of 5th European Conference on Precision Agriculture. 2005; Uppsala. 891-898.

43. Colomina I, Molina P. Unmanned aerial systems for photogrammetry and remote sensing: a review. ISPRS J Photogramm Remote Sens. 2014;92:79-97.

44. European RPAS Steering Group (ERSG). Roadmap for the Integration of Civil Remotely-Piloted Aircraft Systems into the European Aviation Systems: Final Report from the European RPAS Steering Group. ERSG; 2013.

45. Federal Aviation Administration. Integration of Civil Unmanned Aircraft Systems (UAS) in the National Airspace System (NAS) Roadmap. 1 st ed. Washington, DC: US Department of Transportation, Federal Aviation Administration; 2013.

46. van Blyenburgh P, editor. RPAS: Remotely Piloted Aircraft Systems: The Global Perspective. 2013/2014. 11th ed. Paris: Blyenburgh and Co; 2013.

47. Montero FJ, Meliá J, Brasa A, Segarra D, Cuesta A, Lanjeri S. Assessment of vine development according to available water resources by using remote sensing in La Mancha, Spain. Agricultural Water Management. 1999;40:363-375.

48. Arkun S, Honey F, Johnson L, Lamb D, Lieff W, Morgan G. 2000. Airborne Remote Sensing of the Vine Canopy. Vineyard Monitoring and Management Beyond 15-26, 2000. Wagga Wagga: Cooperative Research Centre for Viticulture, National Wine and Grape Industry Centre; 2001. Available from http://www.crcv.com.au/research/programs/one/finalreport.pdf.

49. Johnson LF, Roczen DE, Youkhana SK, Nemani RR, Bosch DF. Mapping vineyard leaf area with multispectral satellite imagery. Computers and Electronics in Agriculture. 2003;38:33-44.

50. Ortega-Farias S, Rigetti T, Sasso F, Acevedo C, Matus F, Moreno Y. Site-specific management of irrigation water in grapevines. Proc IX Congreso Latinoamericano de Viticultura y Enología. November 24-28, 2003; Santiago, Chile. 55-71.

51. Acevedo-Opazo C, Tisseyre B, Guillaume S, Ojeda H. The potential of high spatial resolution information to define within-vineyard zones related to vine water status. Precision Agriculture. 2008;9(5): 285-302.

52. Zarco-Tejada PJ, Berjón A, López-Lozano R, et al. Assessing vineyard condition with hyperspectral indices: leaf and canopy reflectance simulation in a row-structured discontinuous canopy. Remote Sens Environ. 2005;99:271-287.

53. Martín P, Zarco-Tejada PJ, González MR, Berjón A. Using hyperspectral remote sensing to map grape quality in 'Tempranillo' vineyards affected by iron deficiency chlorosis. Vitis. 2007;46(1):7-14.

54. Ruiz-Garcia L, Lunadei L, Barreiro P, Robla JI. A review of wireless sensor technologies and applications in agriculture and food industry: state of the art and current trends. Sensors (Basel). 2009;9:4728-4750.

55. Burrell J, Brooke T, Beckwith R. Vineyard computing: sensor networks in agricultural production. IEEE Pervasive Comput. 2004;3:38-45.
56. Beckwith R, Teibel D, Bowen P. Report from the field: results from an agricultural wireless sensor network. Proceedings of the 29th Annual IEEE International Conference on Local Computer Networks. Nov 2004; Tampa, FL, USA. 471-478.

57. Matese A, Vaccari FP, Tomasi D, et al. CrossVit: enhancing canopy monitoring management practices in viticulture. Sensors (Basel). 2013;13(6):7652-7667.

58. Vellidis G, Tucker M, Perry C, Kvien C, Bednarz C. A real-time wireless smart sensor array for scheduling irrigation. Computers and Electronics in Agriculture. 2008;61(1):44-50.

59. Fisher DK, Kebede H. A low-cost microcontroller-based system to monitor crop temperature and water status. Computers and Electronics in Agriculture. 2010;74(1):168-173.

60. Arduino [homepage on the Internet]. The Arduino Project. Available from: http://arduino.cc/. Accessed February 10, 2015

61. Corwin DL, Lesch SM. Characterizing soil spatial variability with apparent soil electrical conductivity. Part II. Case study. Computers and Electronics in Agriculture. 2005;46:135-152.

62. Samouëlian A, Cousin I, Tabbagh A, Bruand A, Richard G. Electrical resistivity survey in soil science: a review. Soil and Tillage Research. 2005;83:173-193.

63. Zhang X, Smith KA, Worsnop DR, Jimenez J, Jayne JT, Kolb CE. A numerical characterization of particle beam collimation by an aerodynamic lens-nozzle system. Part I. An individual lens or nozzle. Aerosol Sci Technol. 2002;36:617-631.

64. Cerovic ZG, Moise N, Agati G, Latouche G, Ben Ghozlen N, Meyer S. New portable optical sensors for the assessment of winegrape phenolic maturity based on berry fluorescence. J Food Compost Anal. 2008;21(8):650-654.

65. Escolà A, Camp F, Solanelles F, et al. Variable dose rate sprayer prototype for tree crops based on sensor measured canopy characteristics. Proceedings of VI ECPA-European Conference on Precision Agriculture. June 3-6, 2007; Skiathos, Greece. 563-571.

66. Gil E, Escolà A, Rosell JR, Planas S, Val L. Variable rate application of plant protection products in vineyard using ultrasonic sensors. Crop Prot. 2007;26(8):1287-1297.

67. Pérez-Ruiz M, Gonzalez-de-Santos P, Ribeiro A, et al. Highlights and preliminary results for autonomous crop protection. Computers and Electronics in Agriculture. 2015;110:150-161.

68. Vieri M, Sarri D, Rimediotti M, Perria R, Storchi P. The new architecture in the vineyard system management for variable rate technologies and traceability. Acta Horticulturae. 2013;978:47-53.

69. Blackmore S. A vision of farming with robots in 2050. Address to the Oxford Farming Conference. January 8 2014. Oxford, UK. http://www. ofc.org.uk/videos/2014/vision-farming-robots-2050Oxford Farming Conference.

70. VineRobot [homepage on the Internet].The VineRobot project coordinated by Televitis group, at the University of La Rioja in Spain. Available from: http://www.vinerobot.eu/. Accessed February 10, 2015.

71. Robotnik [homepage on the Internet]. Valencia: Robotnik Automation SLL Available from: http://www.robotnik.eu/. Accessed February 10, 2015.

72. Wall-ye softwares and robots [homepage on the Internet]. Available from: http://www.wall-ye.com/. Accessed February 10, 2015.

73. Robotics.bgu.ac.il [homepage on the Internet]. The VineGuard project. Available from: http://robotics.bgu.ac.il/index.php/Development_of an_Autonomous_vineyard_sprayer. Accessed February 10, 2015.

74. Vitirover micro winery robotics [homepage on the Internet]. Saint-Émilion: Vitirover. Available from: http://www.vitirover.com/. Accessed February 10, 2015.

75. Vision Robotics Corporation [homepage on the Internet]. San Diego, CA: Vision Robotics Corporation (VRC). Available from: http://www. visionrobotics.com/. Accessed February 10, 2015.

76. ASI [homepage on the Internet]. Mendon, UT: Autonomous Solutions, Inc. Available from: http://www.asirobots.com/. Accessed February 10, 2015. 
International Journal of Wine Research

Dovepress

\section{Publish your work in this journal}

The International Journal of Wine Research is an international, peer-reviewed open-access, online journal focusing on all scientific aspects of wine, including: vine growing; wine elaboration; human interaction with wine; and health aspects of wine. The journal provides an open access platform for the reporting

of evidence based studies on these topics. The manuscript management system is completely online and includes a very quick and fair peer-review system, which is all easy to use. Visit http://www.dovepress.com/testimonials.php to read real quotes from some of our published authors.

Submit your manuscript here: http://www.dovepress.com/international-journal-of-wine-research-journalisease-journal 